\title{
RESEARCH AND CLINICAL EXPERIENCE IN THE TREATMENT OF THE NEUROGENIC BLADDER BY ELECTRONIC IMPLANT AND PROSTHESES
}

\author{
By SHedden Alexander \\ University Department of Surgery, Royal Infirmary, Glasgow
}

Stages of the investigation.

I. Mechanism of normal bladder control.

2. Experimental bladder evacuation and control.

3. Methods of electrical stimulation in patients.

4. Clinical experience.

I. Mechanism of Normal Bladder Control. Bladder and urethra form a continuous smooth muscle sheet which contracts as a unit and which receives its principal autonomic innervation from a common nerve, the pelvic splanchnic nerve. If connection with the central nervous system is severed, the bladder still empties in response to stretching of detrusor fibres by virtue of intrinsic tonus. That the bladder can achieve the dual functions of storage and evacuation without postulating an anatomical smooth muscle sphincter with reciprocal innervation is due to three factors:

(I) The shape of the bladder and urethra. As the spherical bladder contracts, its diameter diminishes and the contents are expelled; as the tubular urethra contracts it shortens in length, its diameter increases and the resistance to the passage of fluid along the lumen is reduced (Lapides, I958).

(2) The elasticity of the bladder neck, the resting tonus of its smooth muscle fibres, and the extrinsic urethral pressure. Bladder neck in this context extends from internal urethral meatus to urogenital diaphragm and is the so-called 'internal sphincter' (Woodburne, 1960).

(3) The voluntary muscles of the pelvic floor. These are the levator ani, urogenital diaphragm complex and voluntary muscle fibres in the urethral wall, including the external urethral sphincter. These muscles not only act as a secondary physiological sphincter but are an integral part of the reflex act of micturition on command (Bors, I962; Muellner, I963).

2. Experimental Bladder Evacuation and Control by Electrical Stimulation. To secure evacuation of the dog bladder we applied electrodes to the vesico-motor nerve or the bladder surface. To control experimentally-induced incontinence we applied electrodes to the voluntary muscles of the pelvic floor.

Methods of Securing Evacuation. The pelvic splanchnic nerves in the dog are easily displayed and can be stimulated by bipolar electrodes; unilateral stimulation evokes ipsilateral contraction of half the bladder and bilateral stimulation contraction and evacuation of the whole bladder. This is not an easy thing to achieve in man because of the existence of a peri-vesical nerve plexus and the absence of an accessible and easily identifiable vesico-motor nerve trunk. Our animal studies were therefore directed to finding a relatively accessible area on the bladder surface, 
what has been called a neural trigger zone. Such an area exists in the dog at the uretero-vesical junction where the vesico-motor nerve trunk joins the bladder wall.

Using a pair of platinum disc electrodes sutured to this neural trigger zone and ensuring that the electrodes lay in direct contact with the vesico-motor nerve contraction of the canine bladder occurred in nearly every instance in animals of both sexes.

If the electrodes were attached to any other area of the bladder surface only localised contraction of the detrusor took place (fig. I).
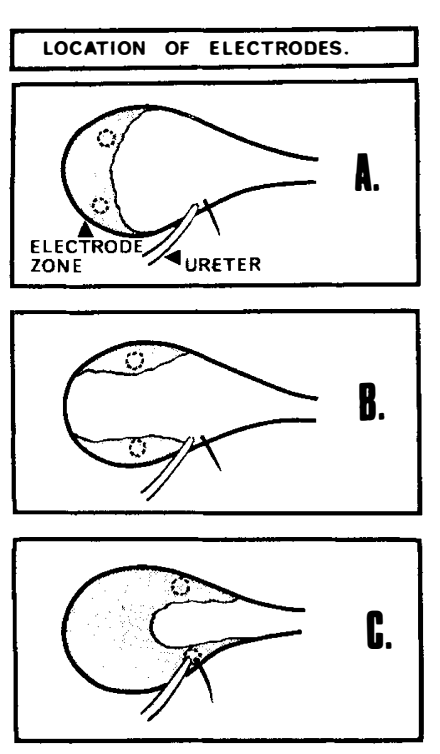

FIG. I

Diagrammatic illustration of detrusor contraction in the dog showing the effect of siting of a pair of electrodes on its surface. Contraction of the whole bladder only occurs when the electrodes are in the vicinity of the parent vesicomotor nerve as in C.

In these experiments electrical stimulation consisted of rectangular pulses of I msec. duration, 20 pulses per second frequency and amplitude 2 to ro volts, delivered by direct linkage to a transistorised stimulator. It was noteworthy that when pulse amplitude exceeded io volts, current spread to the somatic nerves occurred, with contraction of the thigh muscles.

Similar results have been reported in other acute animal experiments and in a chronic basis in intact dogs and animals with spinal cord transection (Kantrowitz et al., I964; Bradley et al., I963; Schoenberg et al., I963; Habib, I963; Glenn et al., I964; Boyce et al., 1964; Ellis et al., 1964; Susset et al., 1967).

Methods of Controlling Incontinence. We employed two preparations to test the effectiveness of stimulation of the voluntary muscles of the pelvic floor in preventing escape of fluid from the bladder, and in each of these stimulated the urogenital diaphragm complex by implanted electrodes, or alternatively the levator ani muscle by an electrode prosthesis which was inserted at an appropriate depth in vagina or rectum.

In the first place we employed the method of inducing the bladder to contract which has been described, and superimposed pelvic floor stimulation.

Transvesical cystometrogram showing a vesical pressure response to bladder stimulation with pelvic floor stimulation superimposed (fig. 2). Note the secondary rise in vesical pressure as the pelvic floor is stimulated.

Electrodes implanted in the lateral part of the urogenital diaphragm were more reliable than vaginal or rectal electrode prosthesis which tended to cause current spread and contraction of thigh muscles; but when the latter were placed at the correct depth there appeared to be little difference between the two methods in respect of pelvic floor contraction and closure of the bladder outlet (fig. 3).

An Artificial Incontinence Preparation. The exposed bladder was filled through the open-ended graduated jar till fluid just escaped from the external urethral meatus, thus simulating incontinence. Pelvic floor stimulation was applied; an additional height to the column in the jar of the order of $20 \mathrm{~cm}$. of water could be accommodated before incontinence occurred (fig. 4). 
In the incontinence experiments the same type of electrical stimulus was applied as in the evacuation experiments, rectangular pulse waves, I msec. duration 20 pulses per second frequency but the pulse amplitude was rather less, 0.5 to 5 volts.

As far as we are aware, animal experiments of the incontinence type have not been reported elsewhere although electrical stimulation of the pelvic floor for in-

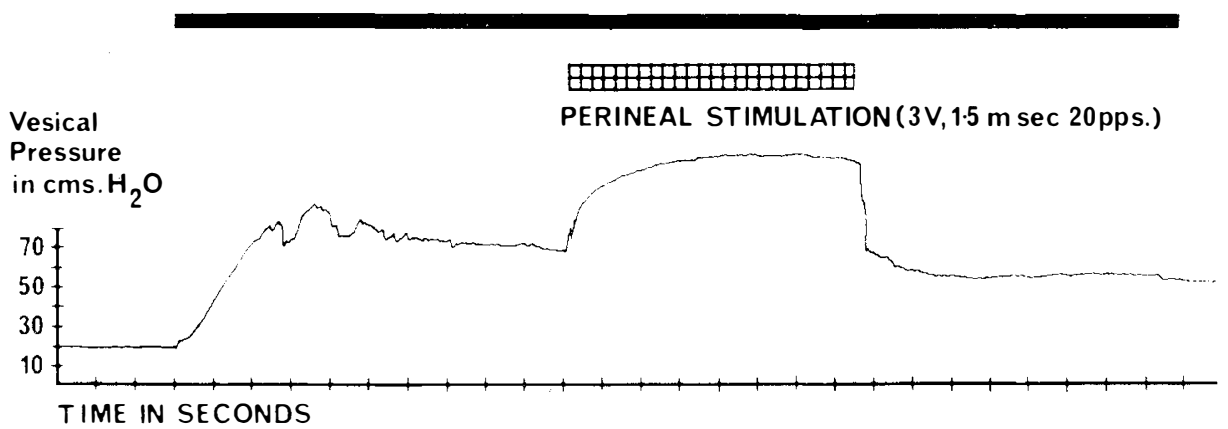

FIG. 2

Transvesical pressure recording from a dog in response to electrical stimulation of the detrusor with perineal electrical stimulation superimposed. The resultant contraction of the perineal muscles is responsible for the second pressure plateau.

EFFECT OF A VAGINAL ELECTRODE ON THE URINARY BPHINCTER MECHANIBM

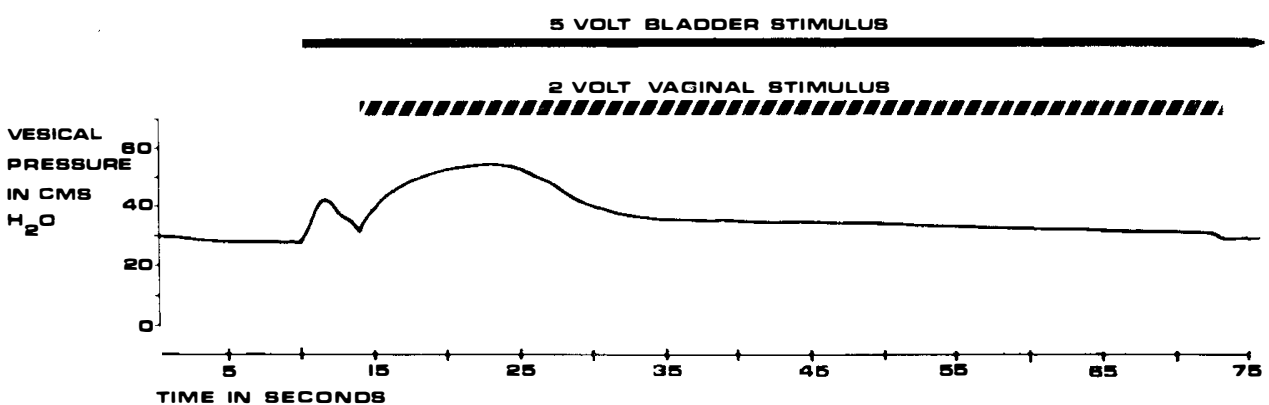

FIG. 3

Transvesical pressure recording from a female dog in response to electrical stimulation of the detrusor with vaginal electrical stimulation superimposed. The resultant contraction of levator ani muscle is responsible for the second pressure rise.

continence in patients has been carried out in Exeter (Caldwell, I963). Our animal experience led us initially to favour implanted urogenital diaphragm electrodes for patients in preference to rectal or vaginal electrode prostheseis and most of the patients who shall be reported in this paper were treated by this method.

We have in recent months, however, found that a vaginal electrode prosthesis, in which a fitted conventional pessary is used as the vehicle for the electrodes, is a 
reliable method of inducing contractions of the levator ani and causes virtually no discomfort to the patient and no contractions of the thigh muscles.

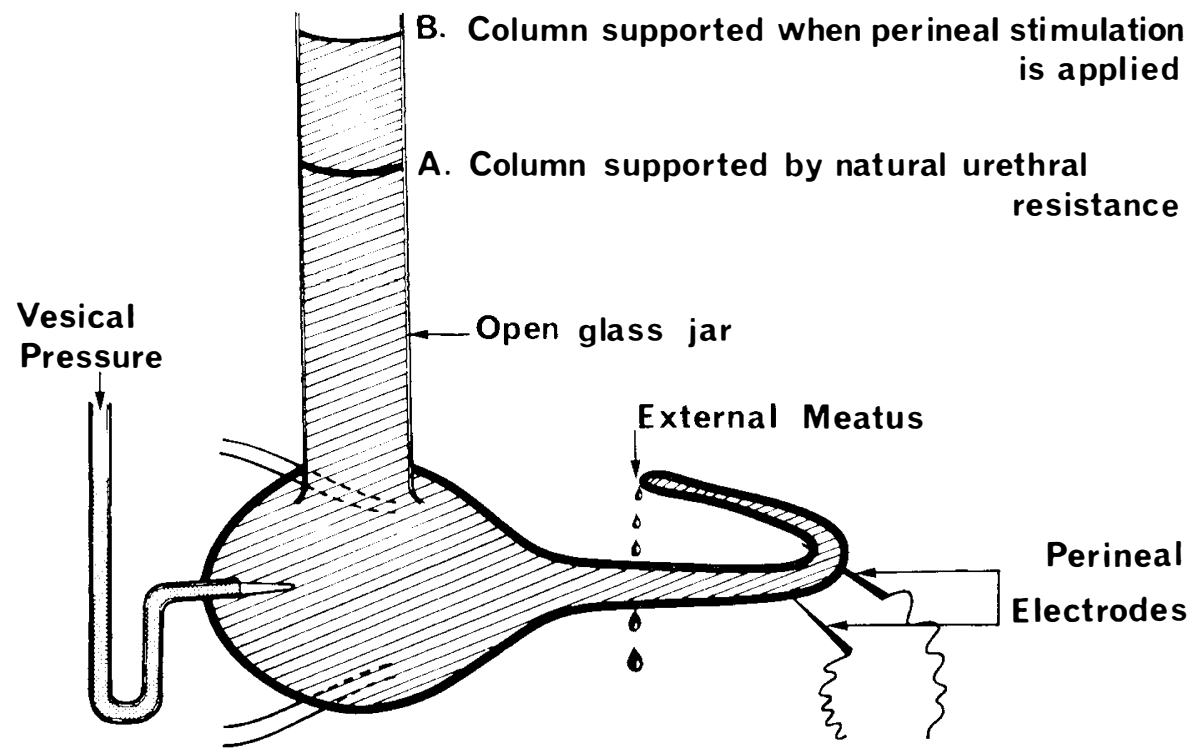

Fig. 4

Diagrammatic illustration of experimentally induced incontinence in a dog. When a perineal electrical stimulation is applied an additional volume of fluid, represented by the column $\mathrm{AB}$, is accommodated before incontinence supervenes.

3. Methods of Electrical Stimulation in Patients. Two basic types of long-term stimulation are employed (I) a radio-implant and (2) an external electrode prosthesis such as the electric pessary. These are manufactured by Devices Ltd., Welwyn Garden City, London.

The Radio-implant. The radio-implant consists of two units (fig. 5). Implanted in the tissues are loop platinum electrodes, leads, and a receiver stimulator. Carried externally is a small portable transmitter connected to an aerial which is placed on the skin overlying the implanted receiver stimulator (fig. 6).

The receiver stimulator consists of a fixed timed circuit and a diode rectifier and filter capacitor which demodulate the radiated signal from the external transmitter before passing it on to the electrodes; it is encapsulated in epoxy resin and covered in medical-grade silicone rubber and, along with leads and electrodes, is sterilised by conventional autoclaving.

The external transmitter contains the batteries and consists of a pulse modulated radio-frequency oscillator feeding the loop aerial. Stimulus intensity can be altered by varying the distance between the aerial and the patient's skin and by a control switch on the transmitter. The stimulus is the same as that used in our animal work, viz., rectangular pulses I msec. duration, 20 pulses per second frequency and, at a coupling distance of 0.5 in., an amplitude, developed across a load of $300 \mathrm{ohms}$ of 4 volts and 7 volts with the 'low' and 'high' power switch positions respectively. The transmitter is carried in an axillary holster. 
The Radio-implant in situ. When the radio-implant is used to secure evacuation of the bladder it is switched 'on' for short periods at the discretion of the patient. When used to treat incontinence the stimulus is, in theory, applied continuously and withdrawn for short periods to permit micturition. In practice some patients with neurogenic incontinence learn to leave the implant switched 'off' and only switch 'on' in anticipation of precipitancy voiding. With continual use in incontinence battery life is short and the batteries require renewal about monthly.

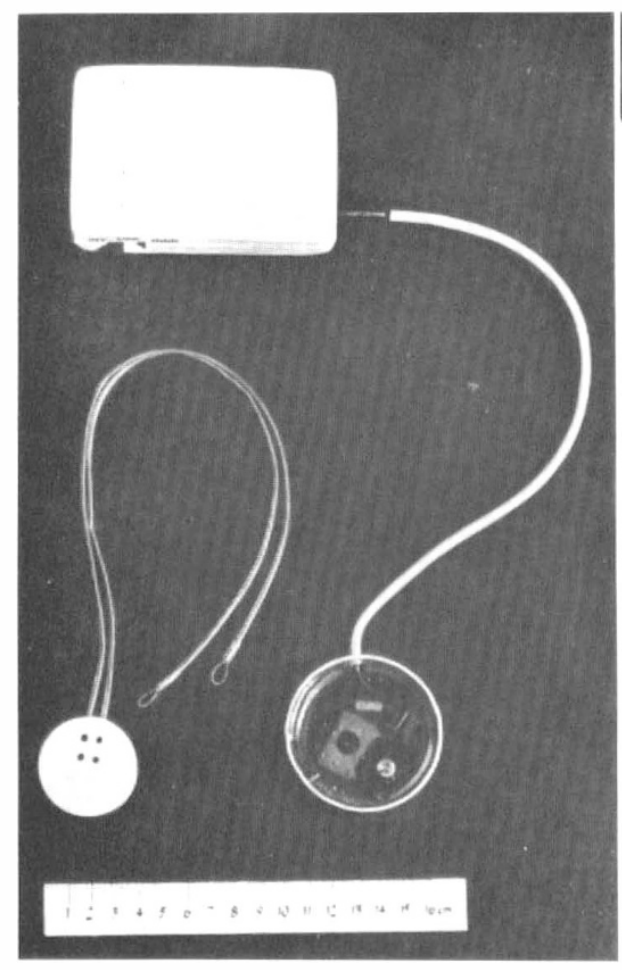

FIG. 5

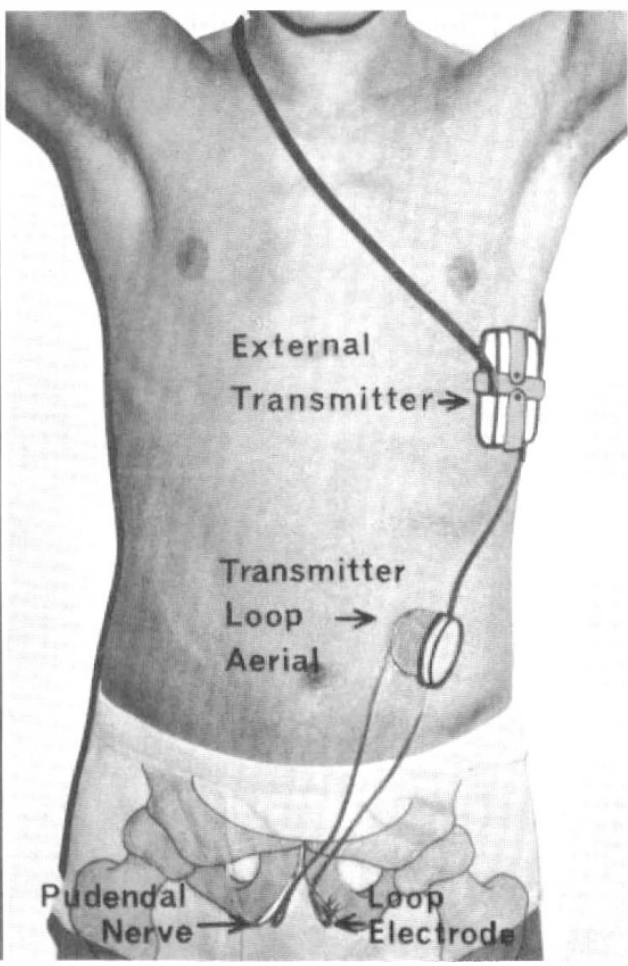

FIG. 6

FIG. 5.-Photograph of the two units comprising a radio-implant: on the left, the implanted receiver-stimulator, leads and electrodes; on the right the external transmitter with aerial.

FIG. 6.-Illustration of a radio-implant in situ.

The Vaginal Electrode Prosthesis or Electric Pessary. A correctly fitting Portex pessary is modified to carry two loops of stainless-steel wires which serve as electrodes and are connected by flexible cable to a miniature battery operated stimulator carried in an axillary holster (fig. 7). The electrodes are placed so that they lie in the anterior segment of the pessary, their mid-points subtending at an angle of 60 to $70^{\circ}$ at the centre of the pessary (fig. 8). In this way the antero-medial fibres of levator ani are subject to maximum stimulation without spread of current to other muscles and somatic nerves in the pelvic wall.

Roentgenogram of the Electric Pessary showing the manner of Incorporation of Electrodes in the Ring (fig 8). A rectal plug with incorporated electrodes has also been used similar to that reported from Birmingham (Hopkinson and Lightwood, 1967). 


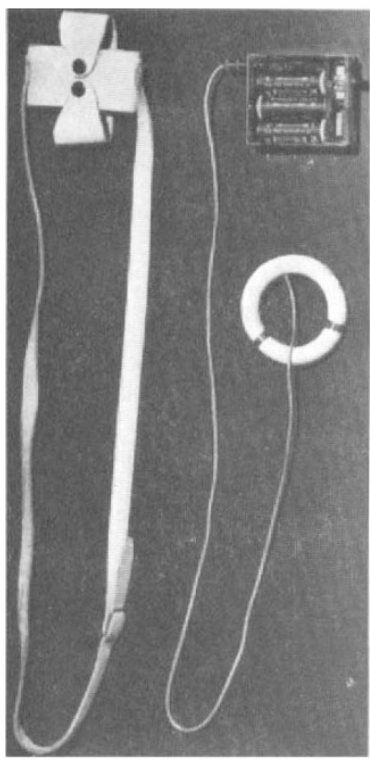

FIG. 7

Photograph of an electric pessary showing direct linkage to a smail stimulator along with holster for the latter.
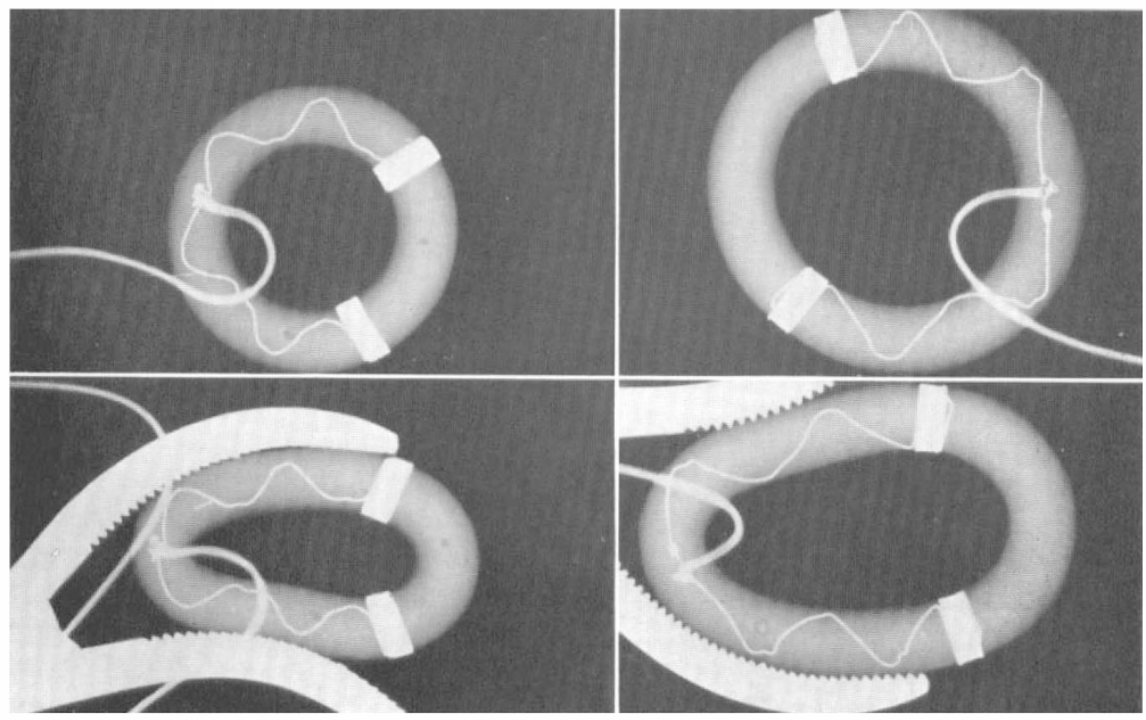

FIG. 8

Radiographs of an electric pessary showing how the manner of incorporating the electrodes permits compression of the pessary. 
4. Clinical Experience. Table I summarises our total clinical experience up to date. Much of this applies to patients with stress incontinence about whom it is not proposed to elaborate.

\section{TABLE I}

Total Number of Radio-implants and Direct Stimulators inserted in Patients GLASGOW ROYAL INFIRMARY

JUNE 1968

\section{Electronic Implants and Prosthesis}

\begin{tabular}{l|l|l|c|c|}
\cline { 3 - 5 } & $\begin{array}{l}\text { Neurogenic } \\
\text { Retention }\end{array}$ & $\begin{array}{l}\text { Neurogenic } \\
\text { Incontinence }\end{array}$ & $\begin{array}{c}\text { Other forms of } \\
\text { Incontinence (stress) }\end{array}$ \\
\cline { 2 - 5 } $\begin{array}{l}\text { BLADDER } \\
\text { ELECTRODS }\end{array}$ & 1 & - & - \\
\hline $\begin{array}{l}\text { PUDENDAL } \\
\text { ELECTRODES }\end{array}$ & - & 8 & 11 \\
\hline $\begin{array}{l}\text { LEVATOR ANI } \\
\text { ELECTRODES }\end{array}$ & - & - & 2 \\
\hline $\begin{array}{l}\text { ANAL SPHINCTER } \\
\text { ELECTRODES }\end{array}$ & - & - & 1 \\
\hline $\begin{array}{l}\text { VAGINAL PESSARY } \\
\text { ELECTRODES }\end{array}$ & - & 1 & 7 \\
\hline $\begin{array}{l}\text { ANAL PLUG } \\
\text { ELECTRODES }\end{array}$ & - & 1 & 2 \\
\hline
\end{tabular}

Neurogenic Retention. We have treated one patient with neurogenic retention by radio-implant.

Case History Summary. This was a 62-year-old woman with urinary retention and indwelling catheter following cerebro-vascular disease.

Cystometry revealed a large hypotonic bladder. Urine was heavily infected. At operation to insert the radio-implant trial stimulation at different points on the bladder surface including the area around the uretero-vesical junction failed to evoke any visible contraction of the detrusor. The electrodes were arbitrarily sited antero-laterally on the bladder surface and the radio-implant inserted.

Following operation a slight rise in vesical pressure was noted when radio-implant stimulation was combined with cholinergic drug. By two months the response to radioimplant stimulation was more marked, a rise of $25 \mathrm{~cm}$. being observed on one occasion, and the patient was able to dispense with an indwelling catheter, the residual urine being 40 per cent. The general well being of the patient was much improved, the urine was sterile, and rehabilitation advanced.

She died 7 months later following a further cerebro-vascular incident. Post-mortem histology of the bladder showed a mild, classical foreign body reaction around the electrodes, characterised by fibrosis, and no evidence of electrolysis.

Although it is felt that intensive rehabilitation efforts and eradication of urinary infection were the prime factor in this patient's improvement, Dr. Hald of Copenhagen (who worked with Dr. Kantrowitz of New York and has used the radio-implant in several patients with neurogenic retention) has told me of a similar delayed response to the radio-implant when none was observed at the time of operation (Hald, I967). 


\section{TABLE II}

Number of Patients and Types of Neurogenic Incontinence treated GLASGOW ROYAL INFIRMARY JUNE 1968

Electronic Implants and Prosthesis INCONTINENT PATIENTS: NEUROLOGICAL DISORDER

\begin{tabular}{|c|c|c|c|}
\hline \multicolumn{3}{|c|}{ U.M.N. } & L.M.N. \\
\hline $\begin{array}{l}\text { CEREBRO - } \\
\text { VASCULAR } \\
\text { DISEASE }\end{array}$ & $\begin{array}{l}\text { DISSEMINATED } \\
\text { SCLEROSIS }\end{array}$ & $\begin{array}{c}\text { MYELITIS } \\
\text { and } \\
\text { Prostatectomy }\end{array}$ & $\begin{array}{l}\text { TRAUMATIC } \\
\text { PARAPLEGIA } \\
\text { Subarachnoid Phenol }\end{array}$ \\
\hline 3 & 3 & 2 & $\mathbf{1}$ \\
\hline
\end{tabular}

TABLE III

Results of Treatment

GLASGOW ROYAL INFIRMARY JUNE 198B

Electronic Implants and Prosthesis

INCONTINENT PATIENTS : RESULTS OF RADIO IMPLANTS

\begin{tabular}{|l|c|c|c|c|}
\hline \multicolumn{1}{|c|}{ RESULTS } & \multicolumn{4}{|c|}{ NEUROLOGICAL DISORDERS } \\
\hline & $\begin{array}{l}\text { CEREBRO VASC } \\
\text { DISEASE }\end{array}$ & $\begin{array}{l}\text { DISSEMINATED } \\
\text { SCLEROSIS }\end{array}$ & MYELITIS & $\begin{array}{l}\text { TRAUMATIC } \\
\text { PARAPLEGIA }\end{array}$ \\
\cline { 2 - 5 } $\begin{array}{l}\text { RESTORED TO } \\
\text { CONTINENCE }\end{array}$ & 1 & - & - & - \\
$\begin{array}{l}\text { MUCH } \\
\text { IMPROVED }\end{array}$ & 1 & 3 & - & - \\
$\begin{array}{l}\text { SLIGHTLY } \\
\text { IMPROVED } \\
\text { NO CHANGE }\end{array}$ & - & - & - & - \\
(Sepsis) & - & 2 & 1 \\
\hline
\end{tabular}

The total number of radio-implants inserted for neurogenic retention and reported in the literature is less than 20 and most of these have been disappointing (Bradley et al., 1963; Kantrowitz et al., 1964; Glenn et al., 1964). One of the most successful reports has come from Montreal (Susset $e t$ al., I968) in which successful 
evacuation has been obtained employing multiple pairs of electrodes on the bladder surface.

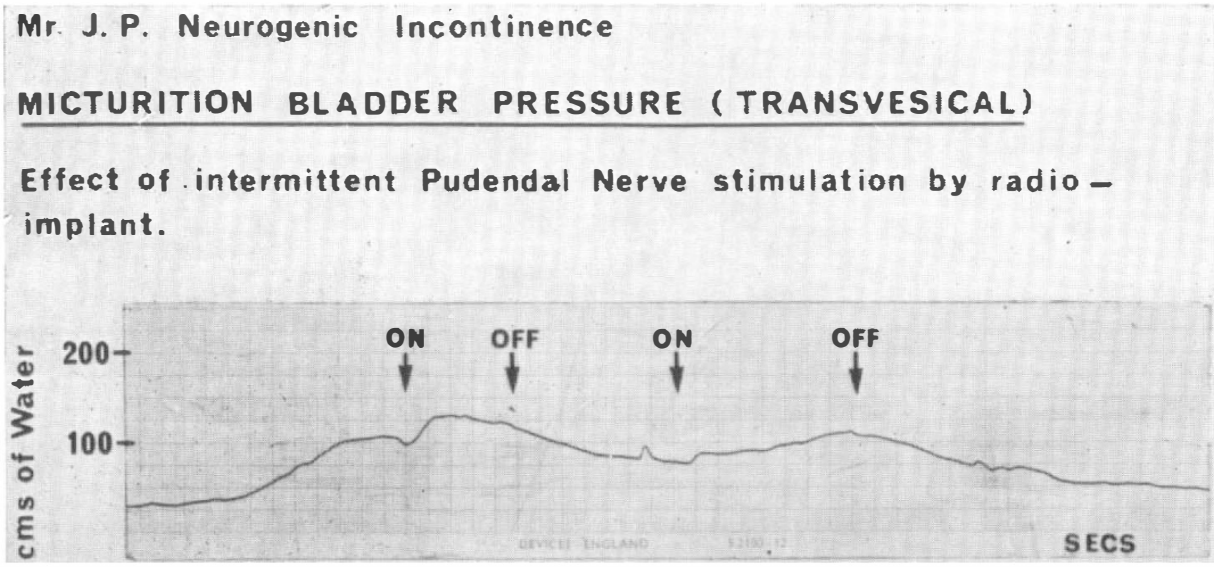

FIG. 9

Transvesical pressure recording from a male patient with neurogenic incontinence in response to willed micturition with two short bursts of radio-implant stimulation superimposed. Note the secondary elevations of vesical pressure.

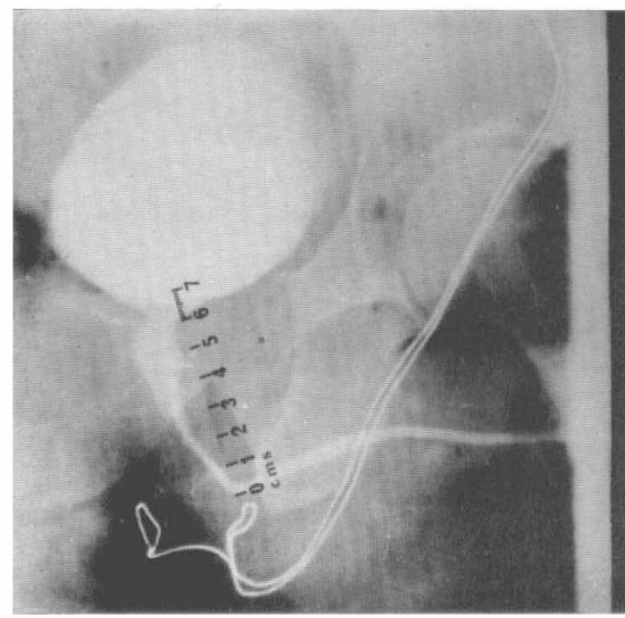

A

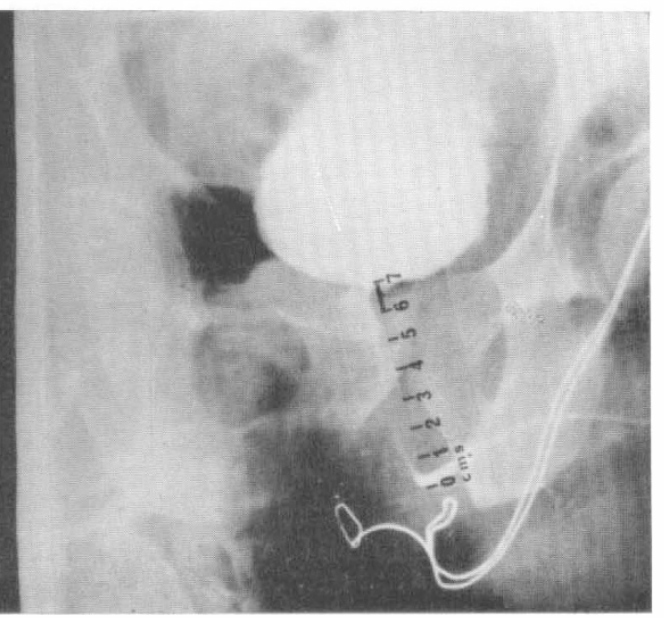

B

FIG. IO

Micturition cystogram in the same patient as Figure 9, naturally (A) and with radio-implant stimulation superimposed (B). Note in (B) the elevation of vesico-urethral junction, elongation of proximal urethra, and interruption of voiding stream.

We are currently working on a simple surgical method of inserting electrodes on the parent pelvic splanchnic nerve by a blind gluteal approach; we feel the insertion of multiple bladder surface electrodes necessitates the implantation of a large amount of foreign material. 
Neurogenic Incontinence. We have treated nine patients, eight with a radioimplant and one with anal plug electrodes (Table II). There were eight with an upper motor neurone lesion, three of whom had cerebro-vascular disease, three cases of disseminated sclerosis and two with myelitis; there was one patient with a lower motor neurone lesion, a traumatic cauda equina lesion with incomplete paraplegia and previous subarachroid phenol instillation. All patients had severe incontinence and four had a permanent indwelling urethral catheter. Bacteriological infection of the urine was the rule. Intravenous pyelograms were carried out in all patients to ensure that both kidneys were functioning satisfactorily.

There were seven men and two women, the majority in the over 60 age group.

Results. The results were encouraging in patients with an upper motor neurone lesion who had not a permanent indwelling catheter (table III). One patient with cerebro-vascular disease was restored to continence and one much improved; the third patient in this group developed post-operative sepsis necessitating removal of the implant. The three patients with disseminated sclerosis were all much improved. Both patients with myelitis had had a prostatectomy and neither was subjectively improved: one patient had a radio-implant and although moderately good contraction of the pelvic floor occurred there was no subjective improvement; the other, who had a permanent indwelling catheter, had anal plug electrodes but no contraction of pelvic floor was observed. We found the anal plug electrode unsatisfactory from a hygienic point of view and would now only use it in patients who have had a diversionary colostomy.

The patient with the lower motor neurone lesion showed no improvement and there was no observable contraction of the pelvic floor on stimulation.

$A$ transvesical cystometrogram in an elderly hemiplegic male with incontinence shows voiding at will with radio-implant stimulation superimposed (fig. 9). Note the secondary elevation in intra-vesical pressure when the implant is switched 'on' indicating an increase in the pressure within the urethra.

A micturition cystogram in the same patient with films taken before and, seconds later, during radio-implant stimulation shows an increase of urethral length during stimulation (fig. Io).

Complications. There was no instance of failure of the electronics in the implanted receiver stimulator or fracture of the implanted leads. All the patients except one tolerated the apparatus; the exception was an elderly hemiplegic male who had lost all desire to help himself and who refused to apply the transmitter at home although demonstrably effective during hospitalisation. Patients experienced a sense of pressure or vibration located in the pelvic region when the implant was switched 'on'; this lasted for a few minutes in some and for the entire period of stimulation in others.

Fate of Implants. The implants have subsequently been removed at operation in four patients on account of local sepsis or pressure-necrosis through skin. The siting of electrodes in the perineum is fairly superficial and it is difficult to prevent contamination of the skin wound in incontinent patients. A second factor is that the receiver stimulator cannot be inserted deep to the deep fascia of the abdominal wall in very stout patients otherwise the radio coupling distance between it and the external transmitter aerial would be too great; thus there is an increased risk of ulceration of the receiver stimulator through skin in very stout patients. 
As an alternative to the surgical insertion of an electronic implant we have invented and developed an electric pessary.

Experience with the Electric Pessary. Our experience of the electric pessary in seven patients with stress incontinence enables us to say that in patients in whom the vagina is not deformed, for instance by previous surgery, and in whom the pessary can be accommodated snugly in the vaginal vault, pelvic floor contraction and control of incontinence is as good as with a radio-implant.

We have recently treated one patient with neurogenic incontinence, a young woman with disseminated sclerosis, with an electric pessary, with an encouraging result. . This patient had had a radio-implant which had to be removed because of ulceration of electrodes through the skin. Both with the radio-implant and the electric pessary there was good pelvic floor contraction and the degree of control of incontinence, was the same. tinence.

We hope to enlarge our experience of the electric pessary in neurogenic incon-

\section{ACKNOWLEDGMENTS}

My close collaborator throughout this work is Mr. David Rowan, Regional Physics Department, Glasgow.

Figs 2, 4, 5, 9 and Io have been reproduced by kind permission from the Brit. Fourn. Surgery.

\section{REFERENCES}

Bors, E. (1962). In Spinal Injuries, ed. Harris, P., Sec. I, p. 33. Edinburgh: Royal College of Surgeons of Edinburgh.

Boyce, W. H., Lathem, J. E. \& Hunt, L. D. (I964). F. Urol. 9I, 4I.

Bradley, W. E., Shelley, N., Chou, S. M. \& French, L. A. (1963). F. Neurosurg. $20,953$. CALDWELl, K. P. S. (1963). Lancet, 2, I74.

Ellis, F., Parker, J. \& Hills, M. (I964). Br. F. Surg. 5I, 857.

GlenN, W. W. L., Hageman, J. H., Mauro, A., Eisenberg, L., Flanigan, S. \& Harvard, M. (1964). Ann. Surg. I60, 338.

Habib, H. N. (1963). Surg. Forum, 14, 489.

HALD, T. (I967). Personal Communication.

Hopkinson, B. R. \& Lightwood, R. (1967). Br. F. Surg. 54, 802.

Kantrowitz, A. \& Schaumaun, M. (1964). F. Am. med. Ass. I87, 595.

LAPIDES, J. (I958). F. Urol. 80, 34I.

Muellner, S. R. (1963). Clin. Obstet. Gynec. 6, I33.

Schoenberg, H. W., Murphy, J. J. \& Young, D. (I963). F. Urol. 89, 820.

Susset, J. G. \& BOCTOR, Z. N. (1967). Invest. Urol. 5, 20.

Susset, J. G. \& Boctor, Z. N. (I968). F. Urol. 98, 673.

WOODBURNe, T. R. (1960). F. Urol. 84, 79 . 


\section{EDITORIAL NOTICES}

The object of Paraplegia, the official Journal of the International Medical Society of Paraplegia, is to publish original papers, reviews and abstracts concerned with all clinical, research and social aspects in the field of injury or disease of the spinal cord. There will also be a section devoted to short papers on techniques and methods of investigation, where these do not form part of original papers or reviews. Proceedings of meetings of the International Society and other associations dealing with problems of paraplegia will also appear.

The Journal is published quarterly, the articles appearing in English with French and German summaries (preferably written by the author).

The Journal should be quoted in lists of references as Int. F. Paraplegia.

Articles offered for publication should be addressed to the Editor of Paraplegia, National Spinal Injuries Centre, Stoke Mandeville Hospital, Aylesbury, Bucks., England.

Manuscripts should be typewritten on one side only of quarto sized paper in double spacing and with a margin of $4 \mathrm{~cm}$. As a rule, papers should be divided into sections, headed by a caption (e.g. Introduction, Materials, Methods, Results, Discussions, Conclusions).

Photographs, microphotographs and radiographs should be printed on glossy paper: they should be submitted unmounted and be clearly marked an the back with the title of the paper and the author's name. Figures and diagrams should be numbered consecutively as figures. Lettering should be done on line drawings, for which good stencils are obtainable; i.e. on the drawings themselves and not on covering transparent paper. Legends to illustrations should be typed on a separate sheet of paper.

References to medical literature should be made in the text, with the name of the author and the year of publication in brackets. At the end of the article, the list of references should be given alphabetically, as follows: Name and initiais of author, year of publication, name of journai (which should be contracted in accordance with the World List of Scientific Periodicals), and number of volume and page. For instance: Rushton, W. A. H. (1961). F. Physiol., 156, 193-205. The name of the author should appear under the title of the paper with his degrees and the name of the hospital or institution from which the paper has been written. When a paper is submitted by authors in collaboration, their names will be printed in alphabetical order.

The Editors cannot accept responsibility for damage to or loss of papers submitted to them. Contributors are advised to keep copies of their manuscripts and illustrations.

Proofs should be corrected carefully and returned without delay. Alterations in print are costly and, apart from verbal correction, will be charged to the contributor.

Subscription Price, payable in advance, is $£ 4$ and the Price of single numbers EI each

Business communications should be addressed to the publishers, Messrs. E. \& S. Livingstone LtD., I5, I6 and 77 Teviot Place, Edinburgh, I. 